\title{
Preserve or sacrifice the stalk? Endocrinological outcomes, extent of resection, and recurrence rates following endoscopic endonasal resection of craniopharyngiomas
}

\author{
Edgar G. Ordóñez-Rubiano, MD,,6 Jonathan A. Forbes, MD,7 Peter F. Morgenstern, MD,1 \\ Leopold Arko, MD,' Georgiana A. Dobri, MD, ${ }^{3,4}$ Jeffrey P. Greenfield, MD, PhD, ${ }^{1}$ \\ Mark M. Souweidane, MD, ${ }^{1}$ Apostolos John Tsiouris, MD, ${ }^{5}$ Vijay K. Anand, MD, ${ }^{2}$ \\ Ashutosh Kacker, MD, BS, ${ }^{2}$ and Theodore H. Schwartz, MD ${ }^{1,2,4}$
}

Departments of ${ }^{1}$ Neurological Surgery, ${ }^{2}$ Otolaryngology, ${ }^{3}$ Endocrinology, ${ }^{4}$ Neuroscience, and ${ }^{5}$ Radiology, Weill Cornell Medical College, NewYork-Presbyterian Hospital, New York, New York; ${ }^{6}$ Department of Neurological Surgery, Fundación Universitaria de Ciencias de la Salud (FUCS), Hospital de San José, Bogotá, Colombia; and 'Department of Neurological Surgery, University of Cincinnati College of Medicine, Cincinnati, Ohio

OBJECTIVE Gross-total resection (GTR) of craniopharyngiomas (CPS) is potentially curative and is often the goal of surgery, but endocrinopathy generally results if the stalk is sacrificed. In some cases, GTR can be attempted while still preserving the stalk; however, stalk manipulation or devascularization may cause endocrinopathy and this strategy risks leaving behind small tumor remnants that can recur.

METHODS A retrospective review of a prospective cohort of patients who underwent initial resection of CP using the endoscopic endonasal approach over a period of 12 years at Weill Cornell Medical College, NewYork-Presbyterian Hospital, was performed. Postresection integrity of the stalk was retrospectively assessed using operative notes, videos, and postoperative MRI. Tumors were classified based on location into type I (sellar), type II (sellar-suprasellar), and type III (purely suprasellar). Pre- and postoperative endocrine function, tumor location, body mass index, rate of GTR, radiation therapy, and complications were reviewed.

RESULTS A total of 54 patients who had undergone endoscopic endonasal procedures for first-time resection of CP were identified. The stalk was preserved in $33(61 \%)$ and sacrificed in $21(39 \%)$ patients. GTR was achieved in 24 patients $(73 \%)$ with stalk preservation and 21 patients $(100 \%)$ with stalk sacrifice $(p=0.007)$. Stalk-preservation surgery achieved GTR and maintained completely normal pituitary function in only $4(12 \%)$ of 33 patients. Permanent postoperative diabetes insipidus was present in 16 patients (49\%) with stalk preservation and in 20 patients (95\%) following stalk sacrifice $(p=0.002)$. In the stalk-preservation group, rates of progression and radiation were higher with intentional subtotal resection or near-total resection compared to GTR $(67 \%$ vs $0 \%, p<0.001$, and $100 \%$ vs $12.5 \%, p<0.001$, respectively). However, for the subgroup of patients in whom GTR was achieved, stalk preservation did not lead to significantly higher rates of recurrence $(12.5 \%)$ compared with those in whom it was sacrificed $(5 \%, p=0.61)$, and stalk preservation prevented anterior pituitary insufficiency in 33\% and diabetes insipidus in 50\%.

CONCLUSIONS While the decision to preserve the stalk reduces the rate of postoperative endocrinopathy by roughly $50 \%$, nevertheless significant dysfunction of the anterior and posterior pituitary often ensues. The decision to preserve the stalk does not guarantee preserved endocrine function and comes with a higher risk of progression and need for adjuvant therapy. Nevertheless, to reduce postoperative endocrinopathy attempts should be made to preserve the stalk if GTR can be achieved.

https://thejns.org/doi/abs/10.3171/2018.6.JNS18901

KEYWORDS minimally invasive; craniopharyngioma; endonasal; endoscopic; pituitary surgery

ABBREVIATIONS ACTH = adrenocorticotropic hormone; $\mathrm{CP}=$ craniopharyngioma; DDAVP = 1-deamino-8-D-arginine vasopressin; $\mathrm{DI}=$ diabetes insipidus; EEA = endoscopic endonasal approach; EOR = extent of resection; GTR = gross-total resection; NTR = near-total resection; RT = radiation therapy; STR = subtotal resection. SUBMITTED April 9, 2018. ACCEPTED June 28, 2018.

INCLUDE WHEN CITING Published online November 23, 2018; DOI: 10.3171/2018.6.JNS18901. 


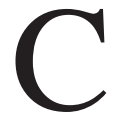
RANIOPHARYNGIOMAS (CPs) are benign rare tumors thought to arise from embryonic remnants of Rathke's pouch. , $, 9,10,43,45$ Gross-total resection (GTR) remains the gold standard treatment of CPs, although comparable control rates have been reported with subtotal resection (STR) and adjuvant radiation therapy (RT). ${ }^{43}$ The development of the endoscopic endonasal approach (EEA) has helped to improve visualization of the sellar and suprasellar region, while eliminating the need for brain retraction and minimizing manipulation of surrounding critical neurovascular structures., . $30,31,45$

There are some cases in which the tumor appears separable from the stalk and stalk preservation is possible. Stalk sacrifice is the alternative strategy that presumably leads to higher rates of endocrinopathy and GTR, but lower rates of recurrence. However, the actual rates of GTR, endocrinopathy, progression, and recurrence after stalk sacrifice are not well understood and are critical to making informed decisions prior to and during surgery. We present a retrospective analysis of a prospective cohort of patients who were treated with EEA for resection of midline CPs. We compared the endocrinological outcomes and the extent of resection (EOR), as well as the progression and recurrence rates depending on whether the stalk was preserved or sacrificed.

\section{Methods \\ Clinical Features}

The authors retrospectively reviewed a prospective database containing records of all patients with midline CPS that were treated via a fully endoscopic, endonasal, extended transsphenoidal approach at the Institute for Minimally Invasive Skull Base and Pituitary Surgery at Weill Cornell Medical College, NewYork-Presbyterian Hospital, between January 2005 and July 2017. Institutional review board approval was obtained for this project. Clinical data including the EOR, stalk preservation, endocrinological outcomes, and postoperative complications were also recorded. The determination of stalk preservation was made by review of operative notes, videos, and postoperative MRI scans. Upon review of the operative note, if the surgeon clearly and unambiguously indicated that the stalk was either sacrificed or preserved, these patients were accordingly categorized. If the stalk preservation could not be determined by the operative note, the operative video was reviewed. If no video was found, then the pre- and postoperative MRI scans were examined for stalk preservation. The MRI scans were subsequently reviewed by 3 separate reviewers and categorized accordingly, to avoid the low specific ability of MRI to definitively document stalk preservation. All patients with prior surgery were excluded due to possible previous manipulation of the stalk, the pituitary gland, or the hypothalamus that could affect the endocrinological outcomes.

\section{Endocrinological Evaluation}

Endocrinological assessment consisted of a full preoperative workup, as well as the results of the last available follow-up postoperative studies, which included cortisol, adrenocorticotropic hormone (ACTH), ACTH-stimulat- ing test, thyroid function tests (thyroid-stimulating hormone, total and free thyroxine, and total and free triiodothyronine when available), growth hormone, insulin-like growth factor-I, and gonadal function, including folliclestimulating hormone, luteinizing hormone, estradiol, total and free testosterone when applicable, and prolactin. Diagnosis of diabetes insipidus (DI) was based preoperatively on preoperative symptoms and postoperatively on the last follow-up if the patient was on replacement with 1-deamino-8-D-arginine vasopressin (DDAVP). Interpretation of endocrine results was based on the endocrinologist notes. Deficiency was diagnosed when the serum levels of endocrinological tests were lower than the current reference values for the axis, and if patients underwent hormone replacement therapy. All neuroendocrine values were retrospectively reviewed by a neuro-endocrinologist (G.A.D.) to address an adequate clinical interpretation. Data that were not available were labeled "unknown." Complications were recorded for each surgery based on postoperative and follow-up visit reports. For those patients who underwent RT the analysis of endocrine outcomes was based on laboratory results within the first 6 months after radiation, since RT itself can produce new or worsening pituitary deficiency with a long interval between treatment and onset. 6,8,29,37

\section{Surgical Procedure}

The surgical nuances of craniopharyngioma resection at our institution have been previously described elsewhere. $7,23,24,38,45$ All surgeries were performed by the senior authors (T.H.S., V.K.A., and A.K.) and assisted by pediatric neurosurgeons (M.M.S. and J.P.G.) in childhood cases. At the beginning of the procedure, a lumbar drain was placed and $0.25 \mathrm{ml}$ of $10 \%$ fluorescein (AK-FLUOR, Akorn) was injected into $10 \mathrm{ml}$ of CSF. ${ }^{33,40}$ Patients were positioned in skull pin fixation for intraoperative neuronavigation. A vascularized nasoseptal flap was raised and set aside in the nasopharynx for subsequent reconstruction. ${ }^{27}$ Wide sphenoidotomy and posterior ethmoidectomy were performed. The bone removal included the top of the sella, tuberculum sellae, and parts of the planum sphenoidale as per size of the tumor noted in neuronavigation. ${ }^{9}$ For tumors above the pituitary gland, the sella was only opened just below the superior intercavernous sinus to open the diaphragma sella. For tumors that extended into the sella, the sella was opened accordingly. Both medial opticocarotid recesses constituted the lateral extent. The tumor was internally debulked and meticulously separated from adjacent neurovascular structures using sharp microdissection. All attempts were made to preserve the stalk if possible, and sacrifice of the stalk was performed at the end of the operation if necessary to achieve a GTR, if that was the goal of surgery. The superior hypophyseal arteries were preserved and the branch to the stalk was sacrificed if required for GTR. We made every attempt to preserve the branches to the chiasm and nerve. The closure was performed with a gasket-seal closure covered with a nasoseptal flap..$^{9,13}$ An onlay piece of autologous fascia lata larger than the bone defect was countersunk with a rigid buttress, such as Medpor (Stryker). The nasoseptal flap was placed over this construct all around and covered 

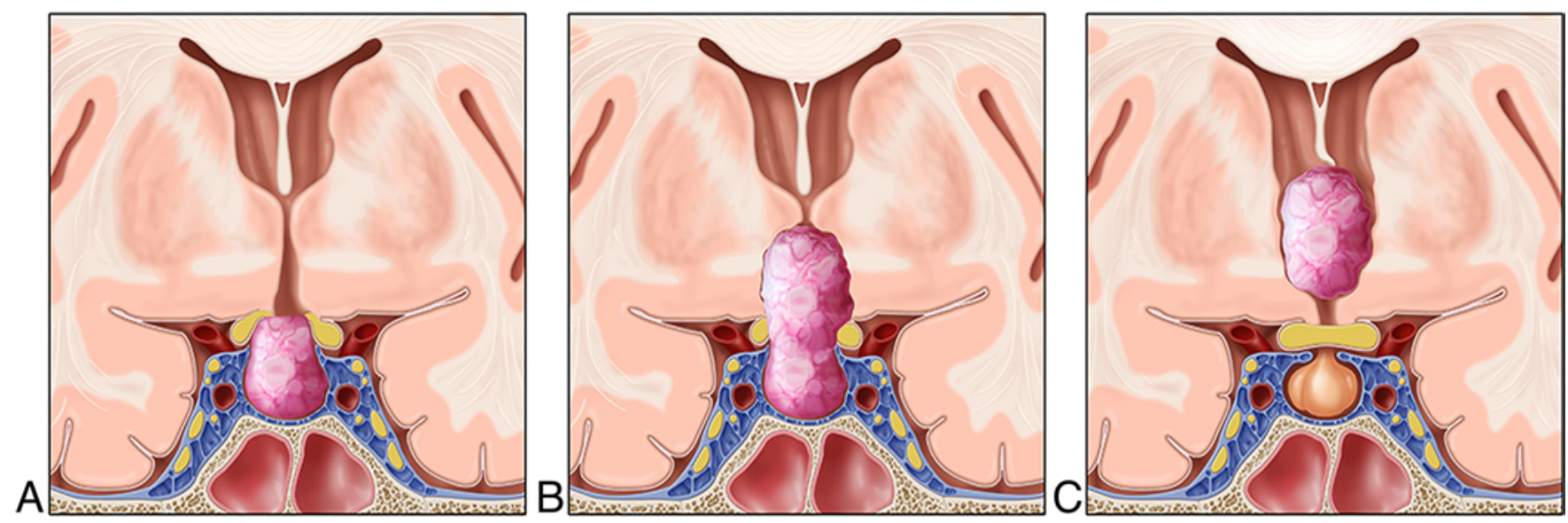

FIG. 1. Illustrations of the simplified 3-tiered classification system of craniopharyngiomas. Images represent coronal T1 postcontrast MRI acquisitions. Type I: sellar tumor without third ventricular invasion or deformation (A). Type II: combined sellar/suprasellar tumor starting in the sella and deforming or invading the third ventricle (B). Type III: purely suprasellar (not shown) or purely intraventricular tumor (C). Copyright Weil Cornell Medical College, NewYork-Presbyterian Hospital. Published with permission. Figure is available in color online only.

with either Duraseal (Integra) or Adherus (Hyperbranch Medical Technology). A lumbar drain was left in place for approximately 24 hours.

\section{Preservation of the Pituitary Stalk, Goals of Surgery, and Extent of Resection}

GTR was the goal of surgery in most cases and we made every attempt to preserve the stalk unless it had to be sacrificed to achieve GTR. STR was the goal of surgery in children with suprasellar tumor to avoid hypothalamic damage, in some elderly patients, in frail patients, and in patients who were young women of childbearing age. In these patients, postoperative radiation was employed to prevent tumor regrowth. ${ }^{1,9}$ Patients with intentional STR were included in the study since there is no clear dividing line between patients in whom as much tumor is removed as possible short of clear damage to the stalk or hypothalamus, regardless of the intention. EOR was divided into GTR (100\%), near-total resection (NTR; $\geq 95 \%)$, and STR $(<95 \%)$ after review of the pre- and postoperative MRI scans by a neuroradiologist (A.J.T.). For cases of STR or NTR, a quantitative analysis of volume for EOR was performed using AW software (version 2.0 Ext 11.0; General Electric). EOR was determined via postoperative enhancement on postcontrast T1-weighted MR images in 7 patients by using the AW software Quick Paint tool for residual tumor. ${ }^{30}$

\section{Classification According to Tumor Topography}

Different classifications have been proposed for craniopharyngioma according to tumor topography. The basis of these classifications was the relation with the diaphragm, ${ }^{44}$ the relation with the ventricle, ${ }^{14,32}$ the tumor extension, ${ }^{36}$ the relation with the stalk, ${ }^{21}$ the growth pattern of the arachnoid envelope around the stalk, ${ }^{35}$ the anatomical extension of the tumor, ${ }^{12}$ the infundibular endoscopic view, ${ }^{18}$ and the anatomical association between the tumor, sellar diaphragm, hypophyseal stalk, and optic nerve. ${ }^{26}$ The re- production of these classifications is difficult due to the variability in the interpretation of the CT and MR images and the multiple types for each classification system, as well as the limited surgical visualization of all the neurovascular structures in relation to these tumors through the different approaches. We used a simplified classification that divided the tumors into 3 groups. Type I are all tumors that arise within the sella, including those with slight suprasellar extension but with no upward deviation of the floor of the third ventricle. Type II includes sella tumors with significant suprasellar extension that deforms or invades the third ventricle. Finally, type III tumors are purely suprasellar with no involvement of the sella (Fig. 1). The MRI scans, including preoperative $\mathrm{T} 1$ postcontrast enhanced coronal and sagittal slices, were reviewed by 3 separate reviewers, including 1 neuroradiologist (A.J.T.) and 2 surgeons who specialize in endoscopic skull base surgery (T.H.S. and J.A.F.). Twenty-two cases $(40.7 \%)$ had complete match between reviewers and 32 cases (59.3\%) had partial match ( 2 of 3 reviewers). If all 3 reviewers agreed, then the patients were categorized accordingly. When 2 of 3 reviewers agreed, cases were categorized according to the majority vote.

\section{Statistical Analysis}

Clinical outcomes, including endocrine and radiological parameters, were compared using the 2-tailed Student t-test or chi-square analysis (Fisher's exact test where appropriate); $\mathrm{p}<0.05$ was considered significant.

\section{Results}

Between 2005 and 2017, 84 endoscopic endonasal extended transsphenoidal surgical procedures were performed for midline craniopharyngioma in 78 patients. Of the 84 procedures, 30 were reoperations for residual/ recurrent tumors and were subsequently excluded. Fiftyfour cases were primary first-time operations and met inclusion criteria. Of these cases, there were 5 type I tumors, 
TABLE 1. Clinical and demographic information

\begin{tabular}{|c|c|c|c|}
\hline Variable & $\begin{array}{l}\text { Stalk Preserved } \\
\qquad(n=33)\end{array}$ & $\begin{array}{l}\text { Stalk Sacrificed } \\
\qquad(n=21)\end{array}$ & $\begin{array}{c}\mathrm{p} \\
\text { Value }\end{array}$ \\
\hline Sex & & & NS \\
\hline Female & $18(54.5)$ & $15(71.4)$ & \\
\hline Male & $15(45.5)$ & $6(28.6)$ & \\
\hline Age in yrs (mean \pm SD) & $43 \pm 24.3$ & $45 \pm 17.2$ & NS \\
\hline Age $\leq 18$ yrs & 7 & 1 & NS \\
\hline \multicolumn{4}{|l|}{$\mathrm{BMI}$ in $\mathrm{kg} / \mathrm{m}^{2}$} \\
\hline Preop & 27.4 & 28.6 & NS \\
\hline Postop & 29.6 & 29.9 & NS \\
\hline $\begin{array}{l}\text { Avg increase in BMl } \\
\text { in } \mathrm{kg} / \mathrm{m}^{2}\end{array}$ & 2.1 & 1.01 & \\
\hline Increased BMI postop & 22 & 10 & NS \\
\hline Pathology & & & NS \\
\hline Adamantinomatous & 25 & 15 & \\
\hline Papillary & 3 & 3 & \\
\hline Not specified & 5 & 3 & \\
\hline Location & & & NS \\
\hline Type I & 4 & 1 & \\
\hline Type II & 11 & 10 & \\
\hline Type III & 18 & 10 & \\
\hline \multicolumn{4}{|l|}{$\begin{array}{c}\text { Tumor vol in } \mathrm{cm}^{3} \text {, } \\
\text { median (IQR) }\end{array}$} \\
\hline Gross & $5.3(3-11.2)$ & $5.1(2.6-7.6)$ & NS \\
\hline Cystic & $4.3(1.8-6.8)$ & $3.5(2.1-5.2)$ & NS \\
\hline Solid & $1.4(0.4-4.2)$ & $0.94(0.39-2.7)$ & NS \\
\hline Recurrence & 3 & 1 & NS \\
\hline Progression & 6 & 0 & 0.043 \\
\hline FU in mos (mean $\pm \mathrm{SD}$ ) & $70 \pm 45$ & $58 \pm 42$ & NS \\
\hline RT & 12 & 0 & 0.001 \\
\hline EOR & & & 0.017 \\
\hline GTR & 24 & 21 & 0.007 \\
\hline NTR & 1 & 0 & NS \\
\hline STR & 8 & 0 & 0.013 \\
\hline
\end{tabular}

Avg = average; $\mathrm{FU}=$ follow-up; NS = not significant.

Values are presented as the number of patients (\%) unless otherwise indicated.

21 type II tumors, and 28 type III tumors. The status of the stalk was determined based on operative notes in 51 cases and MRI review in 3 cases. In 33 of these patients the stalk was preserved and in 21 it was sacrificed. Demographic features of the 2 groups are presented in Table 1 . In the stalk-preserved group, the median age at surgery was 43 years (range $4-85$ years), with 7 children $(\leq 18$ years) and 10 elderly patients ( $\geq 60$ years). In the stalksacrificed group, the median age of patients was 45 years (range 9-67 years), with 1 child ( $\leq 18$ years) and 6 elderly patients ( $\geq 60$ years). There were 20 female and 34 male patients. The most common clinical presenting symptoms included visual loss and headache for both groups (Table 2). Histopathological examination showed an adamantinomatous tumor in 40 patients (74\%), a papillary tumor in
TABLE 2. Clinical presentation

\begin{tabular}{lcc}
\hline \multicolumn{1}{c}{ Presenting Symptom } & $\begin{array}{c}\text { Stalk Preserved } \\
(\mathrm{n}=33)\end{array}$ & $\begin{array}{c}\text { Stalk Sacrificed } \\
(\mathrm{n}=21)\end{array}$ \\
\hline Visual impairment & 24 & 11 \\
\hline Headache & 13 & 7 \\
\hline Cognitive/personality changes & 6 & 1 \\
\hline Seizures & 0 & 1 \\
\hline Vomiting & 1 & 0 \\
\hline Hypothalamic/endocrine & & \\
\hline Memory loss & 3 & 1 \\
\hline Erectile dysfunction & 0 & 1 \\
\hline Amenorrhea & 6 & 5 \\
\hline Balance instability & 2 & 1 \\
\hline Hyperphagia/obesity & 4 & 1 \\
\hline Polyuria/polydipsia & 2 & 2 \\
\hline
\end{tabular}

6 patients (11\%), and CP type not specified in 8 patients (15\%) (prior to BRAF V600/Beta-catenin staining).

\section{Relationship Between Stalk Preservation, Extent of Resection, and Tumor Classification, Progression, and Recurrence}

GTR was achieved in 24 patients (73\%) with stalk preservation and 21 patients $(100 \%)$ with stalk sacrifice $(\mathrm{p}=$ 0.007). In the stalk-preservation cases, there were 8 STRs and 1 NTR with an average preoperative volume of 18.1 $\mathrm{cm}^{3}$, an average postoperative volume of $3.1 \mathrm{~cm}^{3}$, and an average EOR of $81.9 \%$. Although there were trends for impact of tumor classification, the limited numbers of patients were not sufficient to reach statistical significance. Overall, the ability to achieve GTR and preserve the stalk was slightly higher in type I tumors than with type II or type III tumors (Table 3).

RT was given to 12 patients (36\%) in the stalk-preservation group and 0 patients with stalk sacrifice $(\mathrm{p}=0.001)$. RT was performed after surgery when intentional STR or NTR was achieved, or when progression or recurrence was noted in follow-up. Tumor progression occurred in 6 patients $(18 \%)$ in the group with stalk preservation and in $0 \%$ with stalk sacrifice $(p=0.043)$. Reoperation was performed in 2 patients after progression and in 1 patient after recurrence. Prior to recurrence, 3 patients underwent radiographic GTR in the preserved-stalk group, while in the stalk-sacrificed group 1 patient underwent radiographic GTR before recurrence. Additionally, 3 patients who underwent intentional STR without documented recurrence or progression were also treated with RT just after the surgical procedure as adjuvant therapy (Table 4). No recurrence was recorded after RT.

\section{Endocrinological Outcome Relative to Tumor Classification and Stalk Preservation}

After surgery, hyperprolactinemia was present in $27.8 \%$ of patients. New or total (new + persistent) cases of hypocortisolemia were present in $48.1 \%$ and $64.8 \%$, respec- 
TABLE 3. Stalk preservation and extent of resection according to the 3-tier classification system

\begin{tabular}{|c|c|c|c|c|c|c|c|}
\hline Tumor Type & Stalk Sacrificed & Stalk Preserved & $p$ Value & GTR & NTR & STR & $p$ Value \\
\hline Type I (n = 5) & $1(20 \%)$ & $4(80 \%)$ & NS & $5(100 \%)$ & $0(0 \%)$ & $0(0 \%)$ & NS \\
\hline Type II (n = 21) & $10(48 \%)$ & $11(52 \%)$ & NS & $17(81 \%)$ & $0(0 \%)$ & $4(19 \%)$ & NS \\
\hline Type III $(n=28)$ & $10(36 \%)$ & $18(64 \%)$ & NS & $23(82 \%)$ & $1(4 \%)$ & $4(14 \%)$ & NS \\
\hline
\end{tabular}

tively. New or total hypothyroidism was present in $50 \%$ and $70.4 \%$, respectively. New or total hypogonadism was present in $31 \%$ and $52 \%$, respectively. New or total growth hormone insufficiency was present in $22 \%$ and $24.1 \%$, respectively. New or total DI was present in $48.1 \%$ and $66.7 \%$, respectively (Table 5). Tumor type did not correlate with endocrine outcome, except for hypogonadism in the stalk-preserved group $(\mathrm{p}=0.07)$. There were nonsignificant trends for higher rates of hyperprolactinemia in type I $(60 \%)$ compared with type II (18\%) or type III (28.5\%) tumors, likely from higher rates of hypopituitarism after type II and type III surgeries. Hypogonadism was more common in type I (100\%) than in type II (33.3\%) and type III $(57 \%)$ tumors. Finally, DI was less common after type I $(40 \%)$ than after type II $(81 \%)$ or type III $(60.7 \%)$ tumor surgeries (Table 5).

Stalk preservation surgery achieved GTR and maintained normal pituitary function in only $4(12 \%)$ of 33 patients. Overall, stalk preservation surgery maintained normal anterior pituitary function in $8(24 \%)$ of 33 patients and normal posterior pituitary function in $17(51 \%)$ of 33 patients. Stalk sacrifice, on the other hand, resulted in GTR in $100 \%$ but also led to $100 \%$ anterior and $95 \%$ posterior pituitary deficiencies. Of these, $33 \%$ had deficiencies in only 2 axes and 1 patient did not have DI after stalk sacrifice (Tables 5-7). Hyperprolactinemia was similar regardless of whether the stalk was preserved (30\%) or sacrificed (24\%). Stalk sacrifice led to statistically significant increases in both new (71.4\%) and total (90.5\%) hy- pocortisolemia compared with stalk preservation $(33.3 \%$ and $48.5 \%$, respectively; $p<0.001)$. Stalk sacrifice led to statistically significant increases in both new (71.4\%) and total $(90.5 \%)$ hypothyroidism compared with stalk preservation (36.4\% and $57.6 \%$, respectively; $\mathrm{p}=0.001)$. Finally, stalk sacrifice led to statistically significant increases in both new (71.4\%) and total (95.2\%) DI compared with stalk preservation $(33.3 \%$ and $48.5 \%$, respectively; $\mathrm{p}=$ 0.002; Tables 5-7).

Since some of the patients in whom stalk preservation was achieved had intentional STR or NTR, while others had successful GTR, we separated this group into two categories. One would imagine that an intentional STR would have significantly higher rates of normal pituitary function as well as higher rates of progression and radiation. However, GTR with the stalk-preserved group presented higher rates of normal pituitary function (33\%) compared with the STR and GTR with stalk-sacrificed groups (22\% and $0 \%$, respectively; $\mathrm{p}=0.005$ ). Rates of DI, however, were no better following intentional STR (67\%) compared with GTR with stalk preservation (50\%). Rates of progression and radiation were higher with STR compared to GTR with stalk preservation $(67 \%$ vs $0 \%, \mathrm{p}<0.001$, and $100 \%$ vs $12.5 \%, p<0.0001$, respectively; Table 6 ). These results indicate that although a strategy of intentional STR results in similar rates of normal anterior pituitary function and DI, higher rates of progression and radiation are present compared with a strategy of GTR plus stalk preservation.

TABLE 4. Subtotal resections, locations of residuals, progressions, and/or recurrences

\begin{tabular}{|c|c|c|c|c|c|c|c|c|c|c|c|}
\hline $\begin{array}{l}\text { Pt } \\
\text { No. }\end{array}$ & $\begin{array}{c}\text { Age } \\
\text { (yrs) } \\
\text { at Op }\end{array}$ & $\begin{array}{c}\text { Stalk } \\
\text { Preserved }\end{array}$ & $\begin{array}{l}\text { EOR 1st } \\
\text { Procedure }\end{array}$ & $\begin{array}{l}\text { Location of Residual } \\
\text { 1st Procedure }\end{array}$ & $\begin{array}{l}\text { EOR 2nd } \\
\text { Procedure }\end{array}$ & Recurr & $\begin{array}{l}\text { Mos Until } \\
\text { Recurr }\end{array}$ & Progression & $\begin{array}{l}\text { Mos Until } \\
\text { Progression }\end{array}$ & RT & $\begin{array}{l}\text { When Was RT } \\
\text { Performed? }\end{array}$ \\
\hline 1 & 61 & No & GTR & NA & NA & Yes & 29 & No & NA & $\mathrm{No}^{*}$ & NA \\
\hline 2 & 44 & Yes & STR & Stalk \& hypothalamus & NA & No & NA & Yes & 2 & Yes & After progression \\
\hline 3 & 37 & Yes & STR & Stalk & NA & No & NA & Yes & 8 & Yes & \\
\hline 4 & 45 & Yes & STR & Stalk \& hypothalamus & STR & No & NA & Yes & 2 & Yes & After progression \\
\hline 5 & 53 & Yes & NTR & Stalk \& pituitary gland & NA & No & NA & Yes & 18 & Yes & After progression \\
\hline 6 & 26 & Yes & GTR & NA & NA & Yes & 42 & No & NA & Yes & After recurr \\
\hline 7 & 14 & Yes & STR & Stalk \& hypothalamus & NA & No & NA & No & NA & Yes & Prior to op \\
\hline 8 & 7 & Yes & STR & Hypothalamus & NA & No & NA & No & NA & Yes & After intentional STR \\
\hline 9 & 56 & Yes & GTR & NA & NA & Yes & 3 & No & NA & Yes & After recurr \\
\hline 10 & 52 & Yes & GTR & NA & STR & Yes & 11 & No & NA & Yes & After recurr \\
\hline 11 & 52 & Yes & STR & Optic nerve & STR & No & NA & Yes & 1 & Yes & After progression \\
\hline 12 & 4 & Yes & STR & Hypothalamus & NA & No & NA & No & NA & Yes & After intentional STR \\
\hline 13 & 34 & Yes & STR & Optic nerve & NA & No & NA & Yes & 1 & Yes & After progression \\
\hline
\end{tabular}

$\mathrm{NA}=$ not applicable; $\mathrm{pt}$ = patient; recurr = recurrence.

* Patient underwent clinical trial with a BRAF inhibitor for recurrence. 
TABLE 5. Endocrine function after tumor resection

\begin{tabular}{|c|c|c|c|c|c|c|c|c|c|c|c|}
\hline \multirow[b]{3}{*}{ Variable } & \multicolumn{5}{|c|}{ Stalk Preserved $(n=33)$} & \multicolumn{5}{|c|}{ Stalk Sacrificed $(n=21)$} & \multirow{3}{*}{$\begin{array}{c}p \\
\text { Value }\end{array}$} \\
\hline & \multicolumn{3}{|c|}{ Type } & \multirow{2}{*}{$\begin{array}{c}p \\
\text { Value }\end{array}$} & \multirow[b]{2}{*}{ Total } & \multicolumn{3}{|c|}{ Type } & \multirow{2}{*}{$\begin{array}{c}p \\
\text { Value }\end{array}$} & \multirow[b]{2}{*}{ Total } & \\
\hline & $I(n=4)$ & II $(n=11)$ & III $(n=18)$ & & & $I(n=1)$ & II $(n=10)$ & III $(n=10)$ & & & \\
\hline Hyperprolactinemia & & & & NS & & & & & NS & & NS \\
\hline Yes & 3 & 2 & 5 & & 10 & 0 & 2 & 3 & & 5 & \\
\hline No & 0 & 3 & 10 & & 13 & 1 & 5 & 4 & & 10 & \\
\hline Unknown & 1 & 6 & 3 & & 10 & 0 & 3 & 3 & & 6 & \\
\hline Adrenal insufficiency & & & & NS & & & & & NS & & $<0.001$ \\
\hline Persistent & 2 & 1 & 2 & & 5 & 1 & 1 & 2 & & 4 & \\
\hline New & 1 & 5 & 5 & & 11 & 0 & 7 & 8 & & 15 & \\
\hline No & 1 & 4 & 10 & & 15 & 0 & 2 & 0 & & 2 & \\
\hline Unknown & 0 & 1 & 1 & & 2 & 0 & 0 & 0 & & 0 & \\
\hline Hypothyroidism & & & & NS & & & & & NS & & 0.001 \\
\hline Persistent & 3 & 1 & 3 & & 7 & 1 & 1 & 2 & & 4 & \\
\hline New & 0 & 5 & 7 & & 12 & 0 & 7 & 8 & & 15 & \\
\hline No & 1 & 5 & 7 & & 13 & 0 & 2 & 0 & & 2 & \\
\hline Unknown & 0 & 0 & 1 & & 1 & 0 & 0 & 0 & & 0 & \\
\hline Hypogonadism & & & & 0.07 & & & & & NS & & 0.085 \\
\hline Persistent & 1 & 0 & 6 & & 7 & 0 & 2 & 2 & & 4 & \\
\hline New & 3 & 3 & 3 & & 9 & 1 & 2 & 5 & & 8 & \\
\hline No & 0 & 4 & 6 & & 10 & 0 & 2 & 1 & & 3 & \\
\hline Unknown & 0 & 4 & 3 & & 7 & 0 & 4 & 2 & & 6 & \\
\hline Growth hormone deficiency & & & & NS & & & & & NS & & 0.058 \\
\hline Persistent & 0 & 0 & 1 & & 1 & 0 & 0 & 0 & & 0 & \\
\hline New & 1 & 4 & 1 & & 6 & 1 & 2 & 3 & & 6 & \\
\hline No & 1 & 4 & 6 & & 11 & 0 & 1 & 1 & & 2 & \\
\hline Unknown & 2 & 3 & 10 & & 15 & 0 & 7 & 6 & & 13 & \\
\hline DI & & & & NS & & & & & NS & & 0.002 \\
\hline Persistent & 0 & 2 & 3 & & 5 & 0 & 2 & 3 & & 5 & \\
\hline New & 1 & 5 & 5 & & 11 & 1 & 8 & 6 & & 15 & \\
\hline No & 3 & 4 & 8 & & 15 & 0 & 0 & 2 & & 2 & \\
\hline Unknown & 0 & 0 & 2 & & 2 & 0 & 0 & 0 & & 0 & \\
\hline
\end{tabular}

\section{Visual Outcomes, Morbidity, and Mortality}

The 90-day surgical mortality rate for all procedures was $0 \%$. Of the 54 patients, there were 2 with CSF leaks that required repair (4\%) and 1 intracranial infection (2\%). Five patients $(9 \%)$ had postoperative subjective visual worsening and underwent revision of gasket seal closure or hematoma evacuation followed by hypertensive hypovolemic therapy. Four of these patients recovered visual function. One patient (2\%) presented severe vasospasm after the procedure, with consequent bilateral deep infarctions in basal ganglia. Overall visual outcomes were previously reported for this prospective cohort elsewhere. ${ }^{9}$ On long-term follow-up, 2 patients died from prior cardiac/ coronary disease, at 22 and 24 months after surgery, respectively.

\section{Discussion}

Whether to sacrifice or preserve the stalk and whether to attempt GTR or settle for STR are crucial questions facing surgeons during removal of CPs. Surgeons need to understand the impact of each option and its ramifications on endocrine function, ability to achieve GTR, and recurrence rates. Data in the literature are limited on this topic, particularly for the use of the EEA approach. Stalk preservation can be achieved in two ways. Surgeons can intentionally perform an STR or NTR with high likelihood of radiation or tumor progression, which in turn will impact anterior pituitary function. Surgeons can also attempt GTR with stalk preservation. Our main findings are that both strategies are successful at preserving both anterior pituitary function (22\%-33\% of patients) and posterior pituitary function (but only in 50\% of patients). Hence, there is certainly no guarantee that with stalk preservation the patient will not need hormone replacement therapy. Moreover, stalk preservation also significantly reduces the rate of GTR, which in turn increases rates of progression and need for RT, particularly if only STR or NTR is achieved. Many of the patients receiving radiation will also develop a delayed anterior pituitary endocrinopathy, making the 
TABLE 6. Endocrinological outcomes, recurrence, and radiation according to extent of resection

\begin{tabular}{lcccc}
\hline & \multicolumn{3}{c}{ GTR } & \\
\cline { 2 - 4 } & $\begin{array}{c}\text { Stalk Sacrificed } \\
(\mathrm{n}=21)\end{array}$ & $\begin{array}{c}\text { Stalk Preserved } \\
(\mathrm{n}=24)\end{array}$ & $\begin{array}{c}\text { STR+NTR } \\
(\mathrm{n}=9)\end{array}$ & $\begin{array}{c}\mathrm{p} \\
\text { Value }\end{array}$ \\
\hline Any API & $21(100 \%)$ & $16(67 \%)$ & $7(78 \%)$ & 0.005 \\
\hline DI & $20(95 \%)$ & $12(50 \%)$ & $6(67 \%)$ & $<0.001$ \\
\hline Recurrence & $1(5 \%)^{*}$ & $3(12.5 \%)$ & 0 & $\mathrm{NS}$ \\
\hline Progression & 0 & 0 & $6(67 \%)$ & $<0.001$ \\
\hline Radiation & 0 & $3(12.5 \%) \dagger$ & $9(100 \%)$ & $<0.001$ \\
\hline
\end{tabular}

$\mathrm{API}=$ anterior pituitary insufficiency.

* Patient underwent clinical trial with a BRAF inhibitor for recurrence.

$\dagger$ Includes 1 patient who had radiation prior to surgery.

merits of stalk preservation without attempting GTR less clear, unless the patient is a child in whom hypothalamic damage must be avoided, an elderly patient who is unable to tolerate a long complex surgery, or a patient with a giant multicompartmental polycystic tumor in whom GTR is not achievable by any means.

There are few prior studies that have examined this question directly and none in which EEA was utilized. In the original series of Yaşargil et al., the authors reported that the stalk was preserved in $36.5 \%$ of patients, but endocrine function, EOR, and recurrence rates of this subgroup were not analyzed. ${ }^{44}$ Other large early transcranial series of CPs demonstrated similar rates of stalk preservation (approximately 50\%) but did not state explicitly whether stalk preservation impacted GTR rates, progression, or recurrence. ${ }^{11,16,44}$ Van Effenterre and Boch in their series were able to preserve the stalk in 54 patients, of whom only $37 \%$ had normal endocrine function after surgery. ${ }^{41}$ Fahlbusch et al. ${ }^{11}$ and Honegger et al. ${ }^{16}$ also reported similar rates of stalk preservation with DI in 62\% (91\% of transsphenoidal cases) and anterior pituitary dysfunction in a large fraction depending on the axis and the approach. In these early studies, stalk preservation permitted maintenance of endocrine function in roughly half the patients but the impact on GTR rates and progression were not documented.

The largest study of stalk preservation by Xiao et al. examined 203 cases in which the CP was removed transcranially, of which 34 had stalk preservation..$^{42}$ The authors clearly showed that while preservation of the stalk may improve endocrine function after surgery, anterior dysfunction still occurred in $88.3 \%$ and posterior dysfunction in $16 \%$. However, the rates of DI are questionable because even after complete resection of the stalk, only $37.3 \%$ were in patients with DI. The authors also demonstrated that while GTR led to longer survival and fewer recurrences, stalk resection or preservation had no impact on recurrence. However, most patients had radiation after STR and the exact number receiving radiation was not well documented, which likely impacted recurrence rates in a significant fashion. Jung et al. reported a series of 41 adult patients undergoing mostly transcranial surgery for CPs..$^{19}$ In the 24 patients in whom the stalk was preserved, only $33 \%$ were without endocrinopathy. However, preserving the stalk did not impact recurrence rates. These data support our findings that stalk preservation still causes dysfunction in a large proportion of patients but in contrast to their findings, we noted a reduction in GTR and an increase in progression using this strategy. However, it should be noted that in Jung et al.'s study, most patients received radiation, which clearly impacted recurrence rates. Also, these authors did not report whether stalk preservation impacted GTR rates, so it is unclear if stalk preservation similarly reduced rates of GTR. Curiously, this same group published their results in children and found not only that stalk preservation resulted in high rates of endocrinopathy but that recurrence rates also increased. ${ }^{20}$ The authors recommend complete stalk resection as a preferable strategy to prevent recurrence in children. However, they do not clearly report how stalk preservation or sacrifice impacted rates of GTR nor do they report on rates of obesity or cognitive issues. In contrast, in another study in children, Cheng et al. found that in patients with GTR, stalk preservation reduced rates of anterior and posterior pituitary dysfunction with no impact on recurrence. ${ }^{5}$ These authors recommend a strategy of GTR with stalk preservation when this can be achieved. Of note, long-term DI rates in this subgroup were $12.5 \%$, much lower than we report, which may be due to either partial regeneration of the supraoptic pituitary tract or the ability to preserve more of the stalk in the pediatric age group. ${ }^{5}$

In a meta-analysis of the literature from 1999 to 2015, $\mathrm{Li}$ et al. found that stalk preservation reduces rates of endocrinopathy without increasing recurrence rates, thus supporting the strategy of stalk preservation. ${ }^{25}$ These results are based on the papers previously discussed. However, this study has several limitations. As with the other studies, there is no examination of how stalk preservation impacts GTR. Only recurrence rates are scrutinized and this assessment does not examine the rate of radiation, which could cause a low recurrence rate.

Most of the EEA literature describes classification of tumors based on the relationship between the tumor and the stalk, but not the impact of stalk preservation on outcome., ${ }^{3,17,21,22,24}$ Considering this prior literature, our data are novel because they are the first to demonstrate the impact of stalk preservation on rates of GTR, as well as progression, and endocrinopathy. With respect to the impact of stalk preservation on endocrinopathy, the data from most studies concur that endocrinopathy is reduced if the

TABLE 7. Endocrine function before and after tumor resection according to preservation versus sacrifice of the pituitary stalk

\begin{tabular}{|c|c|c|c|c|c|c|c|c|}
\hline & \multicolumn{2}{|c|}{$\mathrm{DI}$} & \multicolumn{2}{|c|}{ API 1 Axis } & \multicolumn{2}{|c|}{ API 2 Axes } & \multicolumn{2}{|c|}{ API $\geq 3$ Axes } \\
\hline & Preop & Postop & Preop & Postop & Preop & Postop & Preop & Postop \\
\hline Stalk preserved $(n=33)$ & $5(15 \%)$ & $16(49 \%)$ & $10(30 \%)$ & $6(18 \%)$ & $5(15 \%)$ & $7(18 \%)$ & $4(12 \%)$ & $12(36 \%)$ \\
\hline Stalk sacrificed $(n=21)$ & $4(19 \%)$ & $20(95 \%)$ & $4(19 \%)$ & 0 & $5(23 \%)$ & $7(33 \%)$ & $3(14 \%)$ & $14(67 \%)$ \\
\hline
\end{tabular}


stalk is preserved but that the patients still run a high risk (approximately 50\%) of permanent DI as well as anterior pituitary dysfunction. In fact, only $12 \%$ of our patients had totally normal pituitary function after stalk preservation surgery. For this reason, patients and treating physicians must be aware that preserving the stalk only maintains hormone function in a minority of cases. Whereas stalk sacrifice in our series resulted in a $100 \%$ GTR rate and only a 5\% recurrence rate, stalk preservation led to a GTR rate of only $73 \%$, with an $18 \%$ progression rate and a $9 \%$ recurrence rate. In 5 of the 9 STR patients, the location of residual tumor was directly involved with the stalk. In addition, preservation of the stalk can also limit manipulation and visualization of residual tumor in other locations like the hypothalamus or even the optic nerve. Patients with STR generally undergo radiation and will likely become hypopituitary, to some degree, from the radiation, further undermining the concept of stalk preservation to preserve endocrine function. The exceptions to this principle are pediatric patients, in whom hypothalamic damage can lead to morbid obesity and cognitive decline, ${ }^{15,28,34}$ as well as elderly patients who may not tolerate any morbidity and patients with multicompartmental, polycystic tumors that may not be fully resectable but are associated with reasonably low morbidity by any means of treatment.

Ultimately, stalk preservation is still an intraoperative judgement call. The goal of surgery should be complete tumor removal with stalk preservation. However, if the stalk appears damaged by the tumor, the patient may be better served by having the stalk sacrificed to ensure GTR. Moreover, a small percentage of patients with stalk sacrifice will avoid DI. If the stalk can be transected inferiorly with some stalk preserved superiorly, patients may not have long-term DI. ${ }^{39}$

\section{Study Limitations}

As a retrospective review, this study has several limitations. For instance, identification of stalk sacrifice relies on the accuracy of the surgical dictation and the sensitivity of MRI for visualizing stalk presence or absence. Identification of subtle DI can be problematic. If patients increase their intake of fluids without taking DDAVP, the diagnosis of DI could be missed. Moreover, the severity of DI is not examined. While some patients have DI that is easily controlled, others have "brittle" DI with varying need for DDAVP, and this difference may be related to partial stalk preservation. Finally, stalk samples were not sent for specific histological analysis of the presence of tumor. The long-term results of STR with radiation compared with GTR with respect to other outcome metrics such as quality of life, return to employment, and fertility are not examined and need to be factored into the equation.

\section{Conclusions}

Our data indicate that while preserving the stalk does hold promise for maintaining some endocrine function, there is still a loss of function in at least $50 \%$ of cases, and if GTR is attempted, in at least $85 \%$. Moreover, preserving the stalk reduces rates of GTR and increases prevalence of tumor progression and the need for radiation. If a surgeon preserves the stalk and achieves GTR, anterior pituitary endocrine function may be preserved. A strategy of intentional STR may work in the pediatric population where minimizing hypothalamic damage is a primary goal of surgery. The stalk should be preserved if GTR is still achievable with its preservation.

\section{References}

1. Alalade AF, Ogando-Rivas E, Boatey J, Souweidane MM, Anand VK, Greenfield JP, et al: Suprasellar and recurrent pediatric craniopharyngiomas: expanding indications for the extended endoscopic transsphenoidal approach. J Neurosurg Pediatr 21:72-80, 2018

2. Baldauf J, Hosemann W, Schroeder HW: Endoscopic endonasal approach for craniopharyngiomas. Neurosurg Clin $\mathbf{N}$ Am 26:363-375, 2015

3. Cavallo LM, Frank G, Cappabianca P, Solari D, Mazzatenta D, Villa A, et al: The endoscopic endonasal approach for the management of craniopharyngiomas: a series of 103 patients. J Neurosurg 121:100-113, 2014

4. Cavallo LM, Solari D, Esposito F, Villa A, Minniti G, Cappabianca $P$ : The role of the endoscopic endonasal route in the management of craniopharyngiomas. World Neurosurg 82 (6 Suppl):S32-S40, 2014

5. Cheng J, Fan Y, Cen B: Effect of preserving the pituitary stalk during resection of craniopharyngioma in children on the diabetes insipidus and relapse rates and long-term outcomes. J Craniofac Surg 28:e591-e595, 2017

6. Combs SE, Thilmann C, Huber PE, Hoess A, Debus J, Schulz-Ertner D: Achievement of long-term local control in patients with craniopharyngiomas using high precision stereotactic radiotherapy. Cancer 109:2308-2314, 2007

7. Conger AR, Lucas J, Zada G, Schwartz TH, Cohen-Gadol AA: Endoscopic extended transsphenoidal resection of craniopharyngiomas: nuances of neurosurgical technique. Neurosurg Focus 37(4):E10, 2014

8. DeVile CJ, Grant DB, Hayward RD, Stanhope R: Growth and endocrine sequelae of craniopharyngioma. Arch Dis Child 75:108-114, 1996

9. Dhandapani S, Singh H, Negm HM, Cohen S, Souweidane MM, Greenfield JP, et al: Endonasal endoscopic reoperation for residual or recurrent craniopharyngiomas. J Neurosurg 126:418-430, 2017

10. Dho YS, Kim YH, Se YB, Han DH, Kim JH, Park CK, et al: Endoscopic endonasal approach for craniopharyngioma: the importance of the relationship between pituitary stalk and tumor. J Neurosurg [epub ahead of print September 29, 2017. DOI: 10.3171/2017.4.JNS162143]

11. Fahlbusch R, Honegger J, Paulus W, Huk W, Buchfelder M: Surgical treatment of craniopharyngiomas: experience with 168 patients. J Neurosurg 90:237-250, 1999

12. Fatemi N, Dusick JR, de Paiva Neto MA, Malkasian D, Kelly DF: Endonasal versus supraorbital keyhole removal of craniopharyngiomas and tuberculum sellae meningiomas. Neurosurgery 64 (5 Suppl 2):269-286, 2009

13. Garcia-Navarro V, Anand VK, Schwartz TH: Gasket seal closure for extended endonasal endoscopic skull base surgery: efficacy in a large case series. World Neurosurg 80:563-568, 2013

14. Hoffman HJ: Surgical management of craniopharyngioma. Pediatr Neurosurg 21 (Suppl 1):44-49, 1994

15. Hoffman HJ, De Silva M, Humphreys RP, Drake JM, Smith ML, Blaser SI: Aggressive surgical management of craniopharyngiomas in children. J Neurosurg 76:47-52, 1992

16. Honegger J, Buchfelder M, Fahlbusch R: Surgical treatment of craniopharyngiomas: endocrinological results. J Neurosurg 90:251-257, 1999 
17. Jane JA Jr, Kiehna E, Payne SC, Early SV, Laws ER Jr: Early outcomes of endoscopic transsphenoidal surgery for adult craniopharyngiomas. Neurosurg Focus 28(4):E9, 2010

18. Jeswani S, Nuño M, Wu A, Bonert V, Carmichael JD, Black $\mathrm{KL}$, et al: Comparative analysis of outcomes following craniotomy and expanded endoscopic endonasal transsphenoidal resection of craniopharyngioma and related tumors: a singleinstitution study. J Neurosurg 124:627-638, 2016

19. Jung TY, Jung S, Choi JE, Moon KS, Kim IY, Kang SS: Adult craniopharyngiomas: surgical results with a special focus on endocrinological outcomes and recurrence according to pituitary stalk preservation. J Neurosurg 111:572-577, 2009

20. Jung TY, Jung S, Moon KS, Kim IY, Kang SS, Kim JH: Endocrinological outcomes of pediatric craniopharyngiomas with anatomical pituitary stalk preservation: preliminary study. Pediatr Neurosurg 46:205-212, 2010

21. Kassam AB, Gardner PA, Snyderman CH, Carrau RL, Mintz AH, Prevedello DM: Expanded endonasal approach, a fully endoscopic transnasal approach for the resection of midline suprasellar craniopharyngiomas: a new classification based on the infundibulum. J Neurosurg 108:715-728, 2008

22. Koutourousiou M, Gardner PA, Fernandez-Miranda JC, Tyler-Kabara EC, Wang EW, Snyderman CH: Endoscopic endonasal surgery for craniopharyngiomas: surgical outcome in 64 patients. J Neurosurg 119:1194-1207, 2013

23. Laufer I, Anand VK, Schwartz TH: Endoscopic, endonasal extended transsphenoidal, transplanum transtuberculum approach for resection of suprasellar lesions. J Neurosurg 106:400-406, 2007

24. Leng LZ, Greenfield JP, Souweidane MM, Anand VK, Schwartz TH: Endoscopic, endonasal resection of craniopharyngiomas: analysis of outcome including extent of resection, cerebrospinal fluid leak, return to preoperative productivity, and body mass index. Neurosurgery 70:110-124, 2012

25. Li K, Lu X, Yang N, Zheng J, Huang B, Li L: Association of pituitary stalk management with endocrine outcomes and recurrence in microsurgery of craniopharyngiomas: a metaanalysis. Clin Neurol Neurosurg 136:20-24, 2015

26. Matsuo T, Kamada K, Izumo T, Nagata I: Indication and limitations of endoscopic extended transsphenoidal surgery for craniopharyngioma. Neurol Med Chir (Tokyo) 54 (Suppl 3):974-982, 2014

27. McCoul ED, Anand VK, Singh A, Nyquist GG, Schaberg MR, Schwartz TH: Long-term effectiveness of a reconstructive protocol using the nasoseptal flap after endoscopic skull base surgery. World Neurosurg 81:136-143, 2014

28. Merchant TE, Kiehna EN, Sanford RA, Mulhern RK, Thompson SJ, Wilson MW, et al: Craniopharyngioma: the St. Jude Children's Research Hospital experience 1984-2001. Int J Radiat Oncol Biol Phys 53:533-542, 2002

29. Minniti G, Saran F, Traish D, Soomal R, Sardell S, Gonsalves A, et al: Fractionated stereotactic conformal radiotherapy following conservative surgery in the control of craniopharyngiomas. Radiother Oncol 82:90-95, 2007

30. Moussazadeh N, Prabhu V, Bander ED, Cusic RC, Tsiouris AJ, Anand VK, et al: Endoscopic endonasal versus open transcranial resection of craniopharyngiomas: a casematched single-institution analysis. Neurosurg Focus 41(6):E7, 2016

31. Omay SB, Almeida JP, Chen YN, Shetty SR, Liang B, Ni $\mathrm{S}$, et al: Is the chiasm-pituitary corridor size important for achieving gross-total resection during endonasal endoscopic resection of craniopharyngiomas? J Neurosurg [epub ahead of print November 24, 2017. DOI: 10.3171/2017.6.JNS163188]

32. Pascual JM, González-Llanos F, Barrios L, Roda JM: Intraventricular craniopharyngiomas: topographical classification and surgical approach selection based on an extensive overview. Acta Neurochir (Wien) 146:785-802, 2004
33. Placantonakis DG, Tabaee A, Anand VK, Hiltzik D, Schwartz TH: Safety of low-dose intrathecal fluorescein in endoscopic cranial base surgery. Neurosurgery 61 (3 Suppl):161-166, 2007

34. Puget S, Garnett M, Wray A, Grill J, Habrand JL, Bodaert N, et al: Pediatric craniopharyngiomas: classification and treatment according to the degree of hypothalamic involvement. J Neurosurg 106 (1 Suppl):3-12, 2007

35. Qi S, Lu Y, Pan J, Zhang X, Long H, Fan J: Anatomic relations of the arachnoidea around the pituitary stalk: relevance for surgical removal of craniopharyngiomas. Acta Neurochir (Wien) 153:785-796, 2011

36. Samii M, Tatagiba M: Surgical management of craniopharyngiomas: a review. Neurol Med Chir (Tokyo) 37:141-149, 1997

37. Schulz-Ertner D, Frank C, Herfarth KK, Rhein B, Wannenmacher M, Debus J: Fractionated stereotactic radiotherapy for craniopharyngiomas. Int J Radiat Oncol Biol Phys 54:1114-1120, 2002

38. Schwartz TH, Fraser JF, Brown S, Tabaee A, Kacker A, Anand VK: Endoscopic cranial base surgery: classification of operative approaches. Neurosurgery 62:991-1005, 2008

39. Shi XE, Wu B, Fan T, Zhou ZQ, Zhang YL: Craniopharyngioma: surgical experience of 309 cases in China. Clin Neurol Neurosurg 110:151-159, 2008

40. Tabaee A, Placantonakis DG, Schwartz TH, Anand VK: Intrathecal fluorescein in endoscopic skull base surgery. Otolaryngol Head Neck Surg 137:316-320, 2007

41. Van Effenterre R, Boch AL: Craniopharyngioma in adults and children: a study of 122 surgical cases. J Neurosurg 97:3-11, 2002

42. Xiao G, Yuan X, Yuan J, Krumtally NA, Li Y, Feng C, et al: Pituitary stalk management during the microsurgery of craniopharyngiomas. Exp Ther Med 7:1055-1064, 2014

43. Yang I, Sughrue ME, Rutkowski MJ, Kaur R, Ivan ME, Aranda D, et al: Craniopharyngioma: a comparison of tumor control with various treatment strategies. Neurosurg Focus 28(4):E5, 2010

44. Yaşargil MG, Curcic M, Kis M, Siegenthaler G, Teddy PJ, Roth P: Total removal of craniopharyngiomas. Approaches and long-term results in 144 patients. J Neurosurg 73:3-11, 1990

45. Zacharia BE, Amine M, Anand V, Schwartz TH: Endoscopic endonasal management of craniopharyngioma. Otolaryngol Clin North Am 49:201-212, 2016

\section{Disclosures}

Dr. Souweidane reports being a consultant for Aesculap, and Dr. Schwartz reports being a consultant for Elliquence and receiving stock options from Visionsense.

\section{Author Contributions}

Conception and design: all authors. Acquisition of data: Schwartz, Ordóñez-Rubiano, Forbes, Morgenstern, Arko, Dobri, Tsiouris. Analysis and interpretation of data: all authors. Drafting the article: all authors. Critically revising the article: all authors. Reviewed submitted version of manuscript: Schwartz, OrdóñezRubiano, Forbes, Arko, Dobri, Tsiouris, Anand, Kacker. Approved the final version of the manuscript on behalf of all authors: Schwartz. Statistical analysis: Schwartz, Ordóñez-Rubiano. Study supervision: Schwartz.

\section{Correspondence}

Theodore H. Schwartz: Weill Cornell Medical College, New York, NY.schwarh@med.cornell.edu. 